\title{
Comprensión del ser como factum de la analítica existecial-ontológica del Dasein
}

\author{
Understanding of being as factum of the \\ existential-ontological analytic of Dasein
}

\author{
CHRISTIAN IVANOFF-SABOGAL \\ Universidad de Heidelberg
}

Recibido: 05/10/2020 Aceptado:27/11/2020

\section{RESUMEN}

La comprensión preontológica del ser es un tema prominente en torno al cual giran constelaciones esenciales de problemas y fenómenos en Ser y Tiempo, al revelarse como el óptimo punto de partida que sostiene a la analítica existencial del Dasein en el horizonte más amplio de la ontología fundamental. Esta investigación atestigua que es el factum inicial fundamental plenamente mostrado y acreditado por Heidegger. Para esta tarea se destaca su despliegue desde su carácter vago y promedio hacia la trascendencia a priori, así como su fundamentación de la intencionalidad, su apertura del ser en general y del Dasein.

PALABRAS CLAVE

HEIDEGGER, SER, MANERAS DE SER, TRASCENDENCIA, INTENCIONALIDAD

ABSTRACT:

The preontological understanding of being is a prominent topic around which essential constellations of problems and phenomena in Being and Time revolve, revealing itself as the optimal starting point that carries the existential analytics of Dasein on the broader horizon of fundamental ontology. This research shows that it is the fundamental initial factum fully shown and credited by Heidegger. For this task we highlight its unfolding from its vague and average character towards the a priori transcendence, as well as its foundation of intentionality, its opening of being in general and of Dasein.

KEYWORDS

HEIDEGGER, BEING, WAYS OF BEING, TRANSCENDENCE, INTENTIONALITY

(C) Contrastes. Revista Internacional de Filosofía, vol. XXVI Nº3 (2021), pp. 69-88. ISSN: 1136-4076

Departamento de Filosofía, Universidad de Málaga, Facultad de Filosofía y Letras

Campus de Teatinos, E-29071 Málaga (España) 


\section{INTRODUCCIÓN}

LA COMPRENSIÓN PREONTOLÓGICA del ser ha recibido escasa atención por parte de la investigación heideggeriana, tomando como criterio la ausencia de un esfuerzo exegético exclusivamente abocado a su indagación y exposición. Esta ausencia es especialmente sorprendente a la luz de unívocos comentarios posteriores de Heidegger. En 1941 aclara retrospectivamente que «con 'comprensión del ser' está nombrado aquello hacia lo que piensa exclusivamente todo en 'Ser y Tiempo'»1. Esta declaración reafirma lo que ya había expresado en 1936 respecto a la identificación de la «pregunta por el ser como pregunta por la comprensión del ser» ${ }^{2}$. Estas afirmaciones parecerían ser suficiente prueba de la radicalidad del alcance temático que guarda la mencionada comprensión dentro de la analítica existencial del Dasein como uno de los dos momentos constitutivos, junto al análisis temporal, de la ontología fundamental. Una tarea interpretativa al respecto sería superflua, si no fuera porque además de que aquellas afirmaciones no traen consigo su aclaración, Heidegger mismo defiende tempranamente en los años 20 que toda «autointerpretación es irrelevante» ${ }^{3}$. Por ello, partiendo de que la comprensión preontológica del ser juega un papel decisivo en tanto factum en el planteamiento inicial de la pregunta por el ser y su sentido, explicaremos sistemáticamente por qué no permanece como mero factum, al estar debidamente mostrada (Aufweisung) y acreditada (Ausweisung). Amén de la dificultad interna de este fenómeno, el escollo principal para su interpretación se sostiene en tres razones interdependientes. Primero, no hay un apartado especial que dedique una tematización exhaustiva a sus rasgos esenciales en su despliegue fáctico ${ }^{4}$. Segundo, es un tema que se presenta disperso a lo largo de Ser y Tiempo (SyT) y las lecciones circundantes. Tercero, está siempre presente como sostén implícito en la indagación de todo otro fenómeno esencial tematizado ontológicamente.

En vista de aquellas dificultades es menester aclarar cómo procedemos. El estatus co-originario de los fenómenos esenciales estudiados por Heidegger en su ontología fundamental conlleva que en la concentración sobre un fenómeno específico esté siempre implicada co-temáticamente la constelación de fenómenos con los que guarda una relación de coordinación. Así, es posible abordar la comprensión del ser a través de algunos fenómenos destacados con los que se concatena y que articulan la exposición:

$1 G A$ 82, p. 289. Para $S y T$ se toma como referencia la traducción de J.E. Rivera.

$2 G A$ 82, p. 102. Nos concentramos en $S y T$ y, en relación a él, en las lecciones.

3 GA 17, p. 81.

4 Incluso sus ocho características esenciales en $G A 31$, pp. 40-44 no pasan de ser un bosquejo. 
I. Se muestra el arraigo existentivo de la comprensión preontológica del ser en base a su vaguedad promedio y cómo a su través se llega al campo de la trascendencia a priori.

II. Se explica que tal comprensión fundamenta ontológicamente la intencionalidad, al presentar el acceso a priori al ente como ente en la apertura del ser en general.

III. Se patentiza su presencia constantemente presupuesta a la luz del ser comprendido en las diversas maneras de ser y de la referencia del Dasein al ser en general.

\section{LA VAGUEDAD PROMEDIO EN ORIENTACIÓN A LA TRASCENDENCIA A PRIORI}

El factum de la comprensión preontológica del ser presenta la piedra angular del inicio de la analítica existencial del Dasein y, además, el suelo asegurado para la pregunta por el ser y su sentido, porque aporta la base para el desvelamiento filosófico de la diferencia óntico-ontológica, la cual es la tesis principal que sustenta toda la investigación fundamental-ontológica, aun cuando no aparezca fijada terminológicamente en $S y T$, sino en una conferencia anterior a la publicación de $S y T$ y en una lección posterior ${ }^{5}$. Sobre el trasfondo de la diferencia ontológica y llamando constantemente la atención sobre el ser del ente respectivamente tematizado todo el trabajo teorético de $S y T$ logra llevar progresivamente la comprensión preontológica del ser en tanto factum a pleno despliegue, mostrándola y acreditándola hermenéuticofenomenológicamente, si bien, y esto es relevante, no directamente, sino en concomitancia con otros fenómenos ontológicamente tematizados, a cuya luz veremos que no permanece como mero «factum» o como mero tema de «especulaciones» ${ }^{6}$.

Aunque Heidegger mencione muchos facta, la tal comprensión no es un factum entre otros. Esto lo sabemos doxográficamente con seguridad gracias a la publicación total de las Obras completas de y sobre 1919-1930, donde aparece explícitamente como factum «originario», «enigmático»y «fundamental» ${ }^{7}$. Sistemáticamente cabe demostrarse por qué necesariamente es así, pues la explicación adecuada de un factum fundamental-originario genera tres dificultades. Primero, si el factum es genuinamente radical, la procedencia del lugar desde donde se lo aborde temáticamente ya lo presupone. Segundo, esta circularidad interpretativa, que enraíza en rasgos esenciales de la estructura ontológica del cuidado (Sorge), es asumida positivamente

5 GA 80.1, p. 165; GA 24, p. 22.

6 Respectivamente Lafont 1994, pp. 42, 47 y Oberdieck 2009, p. 161. Así también van Reijen 2009, p. 12.

7 Heidegger 2006a, p. 5.; GA 3, p. 233 y GA 27, p. 321; GA 31, p. 44; GA 80.1, p. 169. 
por Heidegger cuando afirma que lo decisivo es saltar correctamente hacia dentro del círculo. Tercero, si es el punto de partida fundamental del campo temático al que aún no se ha entrado, se vuelve un problema su primerísima caracterización, pues ¿desde qué punto de partida se determina al punto de partida? Heidegger lidia con estas dificultades mediante una tesis elemental, a saber, «esta comprensión del ser promedio y vaga es un factum» ${ }^{8}$.

Esta vaguedad promedio no es lo central, en el sentido de ser la última palabra al respecto. Más bien se trata de un rasgo que aporta inteligibilidad y transparencia al factum en su presentación inicial, cuya vaguedad promedio corresponde a la cautela de una investigación plenamente consciente de las presuposiciones de su situación hermenéutica. A sabiendas de la interdependencia entre tema y método para Heidegger, la legitimidad temática de tal comprensión vaga y promedio reposa en ser un fenómeno perteneciente al Dasein mismo, como veremos más adelante, mientras que su justificación metodológica radica en su naturaleza «trivial» e irrebatible. P. ej. si alguien levantase una protesta contra la tesis del factum, se tendría que admitir que aquello contra lo que se protesta «es», de modo que ya se lo está comprendiendo de una manera radicalmente elemental como siendo. Así, la actividad escéptica refuerza la verdad de lo que critica - por más «trivial» que sea el carácter de aquella verdad - pues presupone poseer la capacidad de estar comprendiendo algo como siendo, hecho fenoménico expresado justamente por lo que pretende desacreditar, la comprensión preontológica del ser. Ahora bien, dar pie a su investigación filosófica a la luz de supuestas trivialidades no es una actitud ajena a Heidegger, sino que lo acompaña desde sus inicios filosóficos. ${ }^{9}$

Respecto a su introducción «trivial» en $S y T$, sería apresurado preguntar si lo comprendido como siendo es verdadero o falso, real o irreal, etc. Una diferenciación segura sobre el carácter ontológico de algo ya implicaría disponer de un criterio firme sobre el concepto del ser, a cuya contraluz se pueda evaluar plenamente al ente respectivo de acuerdo a qué-es y cómo-es, pues «el ente en el cómo de sus posibles 'determinaciones-como-qué' no está simplemente ahí, sino que es una 'tarea'» ${ }^{10}$, la cual presupone precisamente haber puesto ya la mirada en la comprensión preontológica del ser en su vaguedad promedio en relación a algo que es. Esta vaguedad no delata una opacidad o inseguridad respecto al ser del ente que se comprende como algo que es, sino más bien a la no diferenciación inicial en la que nos expresamos ${ }^{11}$ sobre todo aquello que

8 Heidegger 2006a, p. 5.

9 Cf. GA 58, p. 36.

10 GA 62, p. 379.

11 GA 24, p. 250.

Contrastes vol. XXVI-N³(2021) 
sale al encuentro y que de alguna manera está siendo comprendido como algo que es, p. ej. decimos el camino es, el gato es, la iglesia es, sin diferenciar con precisión cómo comprendemos en su ser aquello que decimos (sea expressis verbis o no) que es. Esta vaguedad promedio acentúa el hecho de que acontece común y corrientemente, pues no es ni un «conocimiento óntico del ente» ${ }^{12}$, ni el resultado lógico de una previa conceptualización teorética sobre el ser. Más bien indica hacia la determinación que hace posible que el Dasein fácticamente siempre se encuentre ya situado existiendo y pudiendo existir, desempeñándose a sí mismo en un mundo abierto que le atañe, con prójimos, animales, útiles, etc.

La comprensión del ser está presupuesta respectivamente en cada comportamiento fáctico del Dasein (que es) con algo o alguien (que es). Heidegger afirma sobre ella sin ambages que «desde siempre ya pertenece al Dasein y está 'viva' en cada trato con el ente» ${ }^{13}$. Que esté existentivamente (existenziell) viva en cada trato se debe a que es la previa condición existencial (existenzial) de posibilidad de cualquier fáctico poder hacer, elaborar, querer, sentir o pensar en absoluto, por lo que es preontológica, ejecutiva (vollzugshaft). Esto quiere decir que es podida por y en el mero hecho de existir como hombres. Así, es un desacierto pragmatista reducirla al «acuerdo compartido en nuestras prácticas respecto a qué entes pueden mostrarse cómo» ${ }^{14}$. Tal lectura deflacionaria, al exponerla como el resultado circunstancial de un conjunto empírico de hombres socializados, desconoce que la comprensión del ser revela la determinación humana esencial sobre cuya base recién es posible cualquier acuerdo compartido, porque aquello sobre lo que uno se pone de acuerdo ya debe estar comprendido como algo que «es». Además, ignora que la comprensión del ser no se reduce a prácticas, donde está presupuesto el horizonte dicotómico entre praxis y teoría, sino que enraíza en el horizonte del comportamiento cotidiano preteorético, el cual es previo a cualquier dicotomía de tal naturaleza.

Así, si la comprensión del ser es el punto de partida, el punto de enfoque de su examinación es su sentido de desempeño (Vollzugssinn) cotidiano preteorético. Al amparo de este enfoque Heidegger alcanza dos cometidos cruciales, uno negativo y otro positivo. El negativo es esquivar la asunción acrítica de que el nivel más fundamental de la apertura del Dasein en el mundo reposa en la interpretabilidad y conceptualidad del esquema sujetoobjeto, en cuya articulación la comprensión del ser sufriría inevitablemente

12 Heidegger 2006a, p. 182.

13 Heidegger 2006a, p. 67.

14 Dreyfus 1991, p. 19, también: Dreyfus 2017, p. 47 y Crowell 2013, p. 68. Cf. GA 28, p. 276. 
una modificación gnoseológica, pues de antemano se la estaría enmarcando en un ámbito derivado que previamente ella misma hace posible, a saber, el de un sujeto distanciado (que es) que objetiva representadoramente algo (que es). Por contraste, lo positivo es abrir en la cotidianidad la posibilidad de captar originariamente y sin modificaciones desajustadas su presencia común y «obvia», es decir, no llamativa, dado que ahí radica su lugar más genuino de anclaje en tanto que factum, el cual precede y está ya operando a las espaldas de una disposición articulada en el horizonte comprendedor-interpretativo del esquema sujeto-objeto. De tal forma, Heidegger puede poner al descubierto tal comprensión en su desempeño vago y promedio, común y corriente en la cotidianidad, en aras de alcanzar cómo está siendo ahí comprendido el ser.

Heidegger debe recuperarla desvelándola progresivamente porque su vaguedad promedio presupone su inmediatez y obviedad, por lo que puede ser pasada por alto fácilmente. Esto se debe a que el Dasein, por lo general, está dirigiendo su atención hacia los entes presentes. La concentración unilateral hacia los entes no se establece contextualmente ni sobreviene desde un influjo externo del que cabría sacudirse ocasionalmente, sino que se trata de un suceso que encuentra su origen formal en el carácter extático de la comprensión del ser y su motivo en la experiencia implícita que el Dasein tiene respecto a su propia finitud desasosegante. La comprensión mencionada posibilita el descubrimiento (Entdeckung) de los entes que han sido dejados comparecer en tanto entes al haber sido comprendidos/abiertos en su ser, por lo cual ella misma permite la posibilidad de que se la pase por alto como lo posibilitador, en la medida que uno puede permanecer dirigido sólo hacia lo posibilitado, hacia los entes comprendidos - estos correlatos comprendidos (qué de la comprensión) no deben confundirse con las modalidades de la comprensión (cómo de la comprensión), así se evita defender ilícitamente un aislamiento del mundo y de los coexistentes para desempeñarse en propiedad, ignorando la independencia óntico-regional de las modalidades ${ }^{15}$. Heidegger explica que el exclusivo y «natural» estar dirigido hacia el ente posibilitado, en detrimento de la comprensión posibilitadora, se debe a que «la experiencia cotidiana con el entorno, que permanece dirigida óntica y ontológicamente hacia el ente intramundano» ${ }^{16}$, ya ha «atravesado» ${ }^{17}$ la comprensión preontológica del ser, porque la presupone como su condición de posibilidad. Por eso la suele olvidar sin ningún reparo e intención - de lo contrario no estaría olvidada. Este olvido refuerza el rasgo implícito y preontológico de la comprensión del ser en cuanto factum fundamental de la existencia, porque incluso estando olvidada

15 Recientemente Escudero Pérez 2010, pp. 197, 207; Tömmel 2013, p. 337.

16 Heidegger 2006a, p. 181.

17 GA 80.1, p. 203.

Contrastes vol. XXVI-N³(2021) 
permanece en plena operatividad, ya que de ella se nutre la posibilitación del olvido mismo, dado que concede la apertura de los entes en tanto entes, hacia los cuales puede dirigirse unilateralmente la atención. Por ello, el «olvido de la comprensión del ser» ${ }^{18}$ en su copertenencia esencial con el ser olvidado ocurre como una consecuencia interna, mas jamás necesaria, de la propia comprensión del ser.

Que el Dasein pueda estar dirigido hacia los entes porque ya ha «atravesado» la comprensión del ser presupone que, «previamente» a la experiencia con los entes, ya está referido a aquella comprensión. Esto le permite a Heidegger hacer patente que el carácter de tal referencia radica en el suceso de trascendencia propio del Dasein. Anterior al esquema ordinal de un sujeto inmanente que desde su inmanencia pasa luego a trascender hacia un objeto trascendente, la previedad de esta comprensión acontece bajo la forma de la trascendencia constante del Dasein en la que éste se constituye como tal, pues él es el trascendente - tesis ya plasmada en $1926^{19}$. Constituido así por la «trascendencia originaria» ${ }^{20}$ se garantiza la referencia comprendedora del Dasein al ser del ente, referencia que es a priori, determinación a la que Heidegger entiende literalmente como «previedad» ${ }^{21}$ ontológico-racional y no cronológica, pues se comprende al ser del ente y al ente en su ser. El ser no se encuentra absuelto en algún trasmundo autónomo. Ser y ente son diferenciables, pero no separables realiter. Esto es lo que expresa la diferencia ontológica $^{22}$ : al ente se lo comprende como tal «desde» el ser, hacia el cual el Dasein existe trascendiendo a priori. De ahí que Heidegger hable sobre la «dependencia del ser respecto a la comprensión del ser, no del ente», porque «sólo cuando hay (ist) comprensión del ser, se vuelve accesible el ente en tanto ente ${ }^{23}$. En ello se acusa que el ser comprendido del ente no es colocado pero sí abierto y hecho accesible por tal comprensión, porque el ser como tal es diferente pero no ajeno modularmente al Dasein.

El rechazo de una concepción modular, es decir, que por un lado exista el módulo Dasein y por otro esté el módulo ser, se debe a que se trata de una trascendencia hacia el ser que pertenece a la estructura extática interna

18 GA 31, p. 42. Cf. GA 80.1, p. 237.

19 Cf. GA 80.1, pp. 166-170.

20 GA 26, 20. NB: La trascendencia mienta un fenómeno unitario pero acentuable desde diversas perspectivas, de suerte que se la identifica con la Zeitlichkeit, la comprensión del ser y el ser-en-el-mundo.

21 Heidegger 2006a, p. 111.

$22 C f$. GA 80.1, pp. 166, 201. La «ontologische Differenz» es temático-explícita, el «ontologischer Unterschied» es preontológico-implícito (GA 24, p. 454), a éste último nos referimos.

23 Heidegger 2006a, p. 212. Para la posible problematicidad de esta tesis desde la perspectiva de una discusión sobre los motivos que dirigirían al «giro», $c f$. Rosales 2018, p. 107. 
de tal comprensión en su ejecución misma. En efecto, el Dasein siempre está trascendiendo proyectivo-comprendedoramente y de hecho ya ha trascendido arrojadamente hacia el ser comprendido, en parte, gracias a su comprensión del ser (primer comprobante). Este estar trascendiendo y estar habiendo ya trascendido hacia el ser explica que jamás experimentamos en nuestra vida cotidiana preteorética a los entes comparecientes como meras presencias desnudas sin más. Dado que los entes están ya trascendidos, se lidia con ellos ya habiéndolos comprendido de una u otra manera en su ser, tal como hace patente paradigmáticamente el detallado análisis en $S y T$ del ente intramundano comprendido significativamente como útil, p. ej. no comprendo y no trato este ente en mi mano primariamente como cosa, sino como pluma con que se escribe. Por eso, haber trascendido comprendedoramente hacia el ser posibilita simultáneamente el descubrimiento concomitante de los entes en tanto que entes.

Así, el desempeño existentivo cotidiano ya ha «atravesado» o sobrepasado (formalmente) - y a causa de ello posiblemente ha "pasado por alto» (impropiamente) - la comprensión del ser como la determinación a priori que posibilita comprender a los entes en su sery, por ende, el comportamiento con los entes. Por este motivo la analítica existencial se mueve en retroceso: mediante la co-tematización del más próximo comportamiento preteorético con los entes cotidianamente comparecientes se los reconduce hacia la comprensión del ser vaga y promedio implícitamente operativa en ellos, reculando así hacia lo ontológicamente a priori: el ser del ente como tema específico. A continuación veremos que el comportamiento con el ente presupone la intencionalidad y que ésta se basa, a su vez, en la apertura comprendida del ser en general.

\section{LA FUNDAMENTACIÓN DE LA INTENCIONALIDAD Y LA APERTURA DEL SER EN} GENERAL

A ojos de Heidegger, el descubrimiento decisivo de la fenomenología husserliana es la intencionalidad, pues rompe la inmanencia del sujeto aislado en su propia consciencia para (re)ubicarlo acertadamente fuera con las «cosas» como correlatos intencionales inextricables a la consciencia. Sin embargo, en muy resumidas cuentas, Husserl se quedaría a medio camino al omitir que la intencionalidad está anticipada por una previa comprensión del ser del ente ${ }^{24}$. Heidegger corregiría esta omisión reinterpretando la fenomenología en sentido hermenéutico, logrando evitar el acceso metodológicamente reflexivo con el que procede la fenomenología husserliana respecto a su campo temático. De ahí que la hermenéutica sea, en sentido primario, el tratamiento por el cual «se da a conocer a la comprensión del ser, que pertenece constitutivamente al

24 Cf. GA 20, p. 103; GA 17, p. 260; GA 24, p. 102; GA 80.1, p. 133. 
Dasein, el sentido apropiado del ser y las estructuras fundamentales de su propio ser ${ }^{25}$. Este proceder hermenéutico le permite a Heidegger despejar el campo originario que le era inaccesible (e invisible) a la reflexividad objetivante: la comprensión del ser en su más elemental anclaje preteorético cotidiano, que anticipa - en sentido meramente analítico-conceptual - al comportamiento y al desempeño existentivo, porque delinea desde sí lo que se comprende como ente, a partir de lo cual se posibilita el correlato del comportamiento.

Heidegger entiende la intencionalidad como «el carácter relacional a priori», esto es, como la «estructura de los comportamientos» ${ }^{26}$. Desde una perspectiva puramente analítico-conceptual y sin pretensiones de desintegrar la unidad interna de la cosa es necesario que, previamente a cualquier relación, los términos entre los que se constituye la misma estén ya descubiertamente abiertos, en este caso el Dasein que se comporta y el ente con el que se comporta. Por ende, en todas las variopintas circunstancias y variaciones de sentido del comportamiento intencional y en toda intricada «multitud de hilos intencionales» ${ }^{27}$ establecida con lo circundante está ya presupuesta la comprensión preontológica del ser, en la cual se abre el Dasein y se descubre el ente. Ahí se revela una relación de fundamentación entre la comprensión del ser que pertenece esencialmente a la totalidad estructural ontológica del cuidado, que abre al Dasein des-cubriendo al ente en su ser, y la intencionalidad que, en tanto estructura relacional, se da en el vínculo del Dasein al ente. La relación de fundamentación se puede esbozar sumariamente como sigue: un ente se presenta desde sí mismo, de tal forma que dada su presencia mostrativa puede ser descubierto en tanto ente al estar siendo comprendido en su ser por un Dasein que lo deja comparecer en tanto ente. Esto se debe a que el Dasein existe, comprendiendo ser, abierto al y para el ser del ente. De esta base ontológica se desprende el poder comportarse hacia algo descubierto como correlato del comportamiento, cuya estructura relacional es la intencionalidad, la cual supone la estructura del cuidado y su constitutiva comprensión del ser. Esta relación de fundamentación se desconoce tanto al afirmar que el cuidado es «el concepto sucesor heideggeriano para 'intencionalidad'» así como al equiparar la intencionalidad con «el descubrimiento de los entes intramundanos» ${ }^{28}$.

Así, en todo comportamiento intencional está pre-supuesto el ser y su comprensión: «el 'presuponer' del ser tiene el carácter del previo poner en vistas al ser, en tanto que desde este avistamiento se articula anticipadamente

25 Heidegger 2006a, p. 37.

26 GA 24, p. 85; cf. GA 26, p. 158; GA 31, p. 41.

27 Adrián Escudero 2010, p. 510.

28 Respectivamente Gethmann 1987, p. 46 y García Norro 2015, p. 178. 
(vorläufig) en su ser el ente dado. Este poner en vistas al ser, que orienta, surge de la comprensión promedio del ser, en la cual siempre ya nos movemos» ${ }^{29}$. Sin disminuir el agradecimiento a Rivera por su eximia labor traductora, aquí «vorläufig» no puede significar «provisionalmente». Tomando rigurosamente en cuenta el contexto del pasaje, la temática trata del horizonte trascendental previo que explica los logros filosóficos de la ontología tradicional aunque ésta carezca de un conocimiento explícito sobre el sentido del ser. Sin duda el pasaje y su contexto tienen también una función metodológica en aras de salvaguardar la investigación frente a posibles objeciones sobre una «circularidad». Sin embargo, Rivera acentúa unilateralmente el aspecto «investigador» de este párrafo (p. ej. cuando añade «sirve de guía a la investigación»), omitiendo que en este contexto lo decisivo radica en que la investigación de Heidegger está legitimando su propio proceder mediante la puesta al descubierto de una comprensión del ser cotidianamente vaga y promedio, sobre la cual se apoya explícitamente; mientras que la ontología tradicional lo hace también, pero tácitamente. Hacer patente la impronta a priori de la comprensión preontológica del ser, a lo que se refiere el «ya nos movemos», obliga a explicitarla en su arraigo cotidiano vago y promedio, desde donde se la desvela como suelo de toda actividad preteorética y también teorética. Mediante ello Heidegger puede evitar que su investigación explícita acerca del sentido del ser repose sobre la base de una construcción no fenomenológica.

$\mathrm{Su}$ impronta a priori (previa) y su alcance irrestricto, al atravesar toda actividad preteorética y teorética, permite concentrarnos exegéticamente en el ser en general. Luego de haber refrendado vigorosamente la relación entre el Dasein y su propio ser, Heidegger lanza una tesis esencial: «es el ser aquello que le compete cada vez como tal a este ente» ${ }^{30}$, esto es, al Dasein. Sin duda, aquí está implicada también la propia existencia, por lo que se afirma que «la indicación formal de la existencia estaba guiada por la comprensión del ser que yace en el Dasein mismo» ${ }^{31}$, pero enfaticemos el tema del ser en general, porque nos ocupa la comprensión del ser, no solo la del propio ser. El Dasein se diferencia de otros entes al ser (pre)ontológico, porque está determinado esencialmente por la relación en la que se encuentra con su propio ser y con el ser en general. Ya que el Dasein no es un sujeto aislado, sino un «ser-con-en-el-mundo» ${ }^{32}$, su comprensión del ser resume e integra la comprensión del ser de los entes que no tienen carácter de Dasein, p. ej. un

29 Heidegger 2006a, p. 8. Además de la consideración contextual, esta lectura se sostiene sistemáticamente, $c f$. Heidegger 2006a, p. 4.

30 Heidegger 2006a, p. 42.

31 Heidegger 2006a, p. 313.

32 GA 24, p. 394. 
gato, así como la comprensión respectiva sobre el ser de los entes que también tienen carácter de Dasein, p. ej. un colega ${ }^{33}$. La comprensión del ser abre y mantiene abierto lo comprendido, lo cual es siempre el propio ser del Dasein y el ser de aquellos entes como condiciones concomitantes de posibilidad de la existencia, pues ésta se desempeña necesariamente en el mundo con los otros. Como el desempeño del Dasein se abre al proyectarse en su existir en el mundo con los otros, al abrir su propio ser abre el ser de los entes y, cooriginariamente, abriendo el ser de los entes abre su propio ser. Esta mutua implicación fenoménica, inscrita ciertamente en la existencia, es hacia lo que indica hermenéutico-fenomenológicamente la comprensión del ser en general.

La imbricación de la comprensión del ser en general en el fenómeno de la existencia se cristaliza en la afirmación: «la idea supuesta de existencia es la prefiguración existentivamente no vinculante de la estructura formal de la comprensión del Dasein en general» ${ }^{34}$. El genitivo «del», que en el español adquiere una condición explícita, presupuesta en la construcción alemana (Daseinsverständnis), delata un sentido simultáneamente subjetivoconstitutivo y objetivo-autoejecutivo. Subjetivo, porque esta comprensión es una determinación fenoménica que pertenece a la constitución existencial del Dasein. Objetivo, pues es la comprensión desempeñada en la que el Dasein se sostiene necesariamente hacia sí mismo como poder-ser existente. Esta comprensión, en tanto que el Dasein es esencialmente ser-junto (Sein-bei) y ser-con (Mitsein), encierra de antemano una comprensión del ser del ente que no comparte su carácter y del ser de los prójimos, por lo que la comprensión del ser, ínsita a la existencia, no sólo hace posible el acceso y la tematización del ser del Dasein, sino del ser de todo ente compareciente en general.

Ejemplifiquemos mediante el útil. Entre los $§ \S 14-18$ de $S y T$ se destaca, entre otras cosas, el involucramiento constitutivo entre el Dasein y el ser del útil en el horizonte significativo del mundo teniendo siempre en cuenta la comprensión del ser ${ }^{35}$, aunque tal vez no suficientemente acentuada. El cuidar de los útiles circunspectivamente (umsichtiges Besorgen) exhibe un sentido óntico y ontológico ${ }^{36}$, porque mienta tanto el comportamiento ocupacional (óntico) con los entes a-la-mano (Zuhandenes) en el mundo entorno así como el descubrimiento ocupacional (ontológico), esto es, la concreción específica del cuidado que descubre los entes según el ser a-la-mano (Zuhandenheit). El comportamiento con el ente a-la-mano es posible porque el Dasein descubre, dejando comparecer, al ente en cuanto ente a-la-mano, lo que presupone

33 Cf. Heidegger 2006a, pp. 85, 123.

34 Heidegger 2006a, p. 313.

35 Cf. Heidegger 2006a, p. 85-86.

$36 C f$. p. ej. Heidegger 2006a, pp. 57, 123. 
rationaliter que ha sido abierto y dejado ser comprendedoramente en su manera de ser como ser a-la-mano y en su carácter ontológico categorial como condición respectiva o de reposo (Bewandtnis) en un para-algo. Si se ignora la duplicidad óntico-ontológica del cuidar circunspectivo y se lo reduce unilateralmente a una "comprensión práctica», una «experiencia cotidiana [...] en un sentido eminentemente instrumental» o un práctico «referirse al mundo de las cosas» la comprensión del ser implícita en la constelación temática queda soterrada ${ }^{37}$.

En suma: dado que al ser del ente no se lo encuentra directamente como si se tratara de un ente, su tematización lo debe destacar y conceptuar partiendo necesariamente de la vivencia cotidiana preteorética con los entes descubiertos como posibles correlatos del comportamiento intencionalmente articulado, en cuya experiencia el ser está siempre implícitamente «co-comprendido» ${ }^{38}$, a saber, gracias a la comprensión preontológica del ser (segundo comprobante). La exposición de la intencionalidad y el ejemplo específico del ser a-la-mano visibilizan que si la dimensión ontológica de los fenómenos tematizados por Heidegger se pasa por alto, es inevitable que la comprensión del ser, acreditada indirectamente en ellos, sea a su vez malentendida como un mero factum.

\section{EL SER COMPRENDIDO EN SUS DIVERSAS MANERAS DE SER Y EL DASEIN}

El ser a-la-mano mencionado es una de las maneras en las que los entes son. El tema de las maneras de ser, de acuerdo a las cuales todo ente es respectivamente comprendido, permite visualizar más cercanamente al ser comprendido y a la referencia que el Dasein guarda con él. Además, la exposición de las maneras de ser clarifica la multivocidad con la que Heidegger se vale del término «ser» (Sein), por lo que orienta nuestra interpretación rectamente hacia la dimensión fundamental-ontológica del análisis heideggeriano, porque - recordemos - nuestra concentración no reposa en la existencia que comprende su ser pudiendo ser, sino en la acentuación de la comprensión del ser en general.

Ante todo fijemos terminológicamente «manera de ser» como la modalidad del ser que determina la «manera-en-la-que-se-es», el «ser-cómo» del ente respectivo ${ }^{39}$. P. ej. ¿cómo es el Dasein? Éste existe (Existenz). ¿Cómo es el cuervo? Éste vive (Leben). ¿Cómo es el traje? Éste es a-lamano (Zuhandenheit), etc. Esta precisión conceptual es relevante, porque «manera de ser» (Seinsweise) y «tipo de ser» (Seinsart) no están distinguidas

37 Respectivamente Okrent 1988, p. 10, Rubio 2015, p. 75, Volpi 2012, p. 96.

38 GA 80.1, p. 171.

39 GA 24, pp. 24, 415; $C f$. Heidegger 2006a, p. 183; GA 24, p. 36; GA 26, p. 159; GA 27, p. 71. 
terminológicamente y frecuentemente son utilizadas por Heidegger como sinónimos, incluso en un mismo párrafo ${ }^{40}$. Por esta razón, inclinarse por una u otra es una cuestión discutible. Valgan dos ejemplos: von Herrmann, si bien generalmente comprende Seinsweise en sentido ontológico como manera de ser" ${ }^{41}$, asume también esta elasticidad cuando a veces identifica «manera de ser» y «tipo de ser» ${ }^{42}$, luego de haber definido y captado «tipo de ser» en el sentido de «posibilidad de ser» ${ }^{43}$ o $\left\langle p o s i b i l i d a d\right.$ de la existencia ${ }^{44}$. Por otro lado, Rodríguez capta Seinsart como manera de ser ${ }^{45}$. Nuestra elección no es arbitraria, ya que busca apartar cautelosamente la temática del esquema géneroespecie, pues en alemán «art» puede traducirse también como «especie».

Las maneras de ser reflejan que la tematización heideggeriana del ser comprendido no consiste en «recopilar los significados» ${ }^{46}$ de las palabras «ser»y «es» mediante una descripción empírica que constate los diferentes significados implicados en sus múltiples usos. La meta no apunta a la delimitación del campo semántico de «ser», sino, en parte, a poner de manifiesto las maneras de ser en que se comprenden los entes en la cotidianidad preteorética. Al pasar la dimensión ontológica por alto surge la infundada objeción, porque toma por prioritario lo derivado, de que Heidegger confunde y no aclara los «significados» de ser como existencia, cópula, identidad y ser verdadero $^{47}$ - objeción doxográficamente errada ${ }^{48}$. En efecto, la «existencia» expresa la manera de ser propia del Dasein, la cual es una entre muchas. Esta constatación permite, además, evitar homologar el ser en general a la existencia del Dasein, esto es, interpretar que «el ser en general es al mismo tiempo su propio ser» ${ }^{49}$, el propio ser del hombre, se entiende. Por su parte, el análisis del útil no sólo permite develar pormenorizadamente el afincamiento esencial del Dasein en el horizonte de la mundanidad significativa, sino que también recupera filosóficamente la manera de ser a-la-mano, por lo que el estudio hermenéutico-fenomenológico del útil no consiste en una descripción

$40 C f$. Heidegger 2006a, pp. 11, 60, 241; GA 80.1, p. 187. Para los escasos listados sobre las maneras de ser, $c f$. $G A 23$, p. 17; GA 24, pp. 14, 396; GA 25, p. 19; GA 26, p. 191; GA 27, p. $71 ; G A 80.1$, p. 234.

41 P. ej. von Herrmann 2000, p. 137. Sobre todo en su última publicación, von Herrmann 2019 , pp. $40,71$.

42 von Herrmann 1991, p. 46.

43 von Herrmann 1987, p. 102.

44 von Herrmann 2005, p. 41.

45 Rodríguez 2006, p. 60.

46 GA 31, p. 54

47 Tugendhat 1979, p. 169; Tietz 2005, p. 43.

48 GA 24, p. 287; cf. GA 28, p. 274; GA 31, p. 42.

49 Hernández-Pacheco 1983, p. 54; así también Davoli 2013, p. 52. 
sobre cómo se manejan los bolígrafos, así como tampoco una reducción de todo ente a instrumento para el hombre ${ }^{50}$.

Al amparo de la precisión terminológica y de la aclaración del campo temático de las maneras de ser nos facultamos para captar que a la comprensión del ser le atañe un carácter omniabarcante: «comúnmente decimos que está siendo todo lo que de alguna manera comparece en tanto ente, sin reparar en la diferenciación entre maneras de ser determinadas ${ }^{51}$. El rasgo omniabarcante no es el resultado de la suma de los entes comprendidos, porque la suma resultante a la que se pretende llegar y que orienta al sumar también estaría siendo previamente comprendida como ente. Más bien los abarca a todos al ser la condición de posibilidad por la que pueden comparecer como siendo de esta o aquella manera. Remarcando su alcance omniabarcante, Heidegger afirma que la «comprensión preontológica del ser abarca ciertamente todo ente abierto esencialmente en el Dasein; sin embargo, la comprensión del ser misma todavía no se ha articulado de acuerdo a los diversos modos de ser ${ }^{52}$, por lo que los modos (i.e. maneras) de ser no están comúnmente diferenciados los unos de los otros, ya que las «modificaciones posibles del ser», esto es, «la variedad interna de las maneras de ser a partir de la idea del ser» permanecen tanto en el desempeño de la vida cotidiana como también en la ontología tradicional «no temáticas e incluso indiferenciadas» $»^{53}$. La introducción de su impronta omniabarcante explica por qué cualquier ente puede estar articulado en un mismo horizonte unitario que nivele tácitamente las diversas maneras de ser. Esta nivelación acontece en la absolutización de una de las maneras de ser, en cuya absolutización nos mantenemos invidentes respecto a las diversas maneras de ser de los entes descubiertos.

La idea directriz implícita del ser está dada a partir de la manera de ser absolutizada del ser a-la-vista (Vorhandenheit) en sentido amplio, como resultado parcial de la «primacía del 'ver'» ${ }^{54}$ en el hombre. Esto no quiere decir que el trato con el útil en su ser a-la-mano sea imposibilitado sobre la base de que el Dasein no es sino un espectador aislado que observa la realidad descomprometidamente en actitud distanciada. Empero, la noción explícita del ser no la aporta el ser a-la-mano, preteoréticamente porque su sentido radica en velarse a sí mismo en el uso y teoréticamente porque el acceso de la ontología tradicional a su tema reposa en una «mirada» que se «distancia» de lo

50 Malentendido renovado periódicamente con matices, $c f$. Habermas 1983, p. 177; Meike 2010, p. 115.

51 GA 24, p. 250.

52 Heidegger 2006a, pp. 200, 201.

53 GA 24, p. 24; GA 3, p. 295; Heidegger 2006a, p. 324.

54 Heidegger 2006a, p. 171. Para el sentido amplio y estricto de Vorhanden, cf. von Herrmann 1987, p. 103. 
tematizado; el sentido de vinculación (Bezugssinn) del mirar no puede acceder $\mathrm{y}$, por ende, descubrir al útil en su sentido de desempeño originario, en su uso no llamativo. Afín vale para la existencia. Aquella nivelación no significa que el Dasein no esté en condiciones de poder existir con plena familiaridad en su vida cotidiana. Pero la existencia no puede presentarse como la manera de ser dirigente, ya que la nivelación se explica en último término por el ocultamiento y olvido de la existencia dado su carácter desasosegante en base a su finitud intrínseca. Por eso, en la nivelación «la comprensión del ser vulgar comprende indiferentemente 'ser' como ser a-la-vista» ${ }^{55}$. La comprensibilidad e interpretabilidad de todo ente según aquella indiferencia niveladora oculta toda otra manera de ser que no sea la del ser a-la-vista, sea porque su sentido se constituye al no prestarle atención en el uso (ser a-la-mano) o porque es inherentemente desasosegante (existencia).

Manteniendo la vista en el ser comprendido en general, la exposición de las diversas maneras de ser y su posible nivelación tenía como meta lo siguiente: el ser a-la-vista puede absolutizarse preontológicamente sobre la base de que las maneras de ser son lo comprendido en el ente y de que la nivelación concomitante a tal absolutización implica necesariamente la posibilidad del acceso comprendedor a todas las maneras preteoréticas de ser y esto gracias a la comprensión preontológica del ser (tercer comprobante).

La comprensión del ser que abre en el ente al ser comprendido como la unidad plegada que se articula fácticamente en las diversas maneras desplegadas de ser y el hecho ahí delatado de que hay un ser comprensible es lo que instituye al Dasein y lo que acredita la captación fenomenológica del hombre como Dasein $^{56}$. Lo relevante para nuestro tema es reparar que «Dasein» no se fundamenta aisladamente a sí mismo, sino únicamente por su referencia al ser. Esta referencialidad es circular, porque tanto el ser como el Dasein están trabados recíprocamente, si bien es inevitable que la investigación heideggeriana parta de un ente, del Dasein. Veamos la circularidad. 1. El Dasein se determina como tal en base a su referencia constitutiva a la apertura del ser, a partir de la cual se lo acredita como Dasein (Dasein desde ser) 2. Sin embargo, la apertura del ser sólo está abierta, es mantenida abierta y es accesible en la comprensión preontológica del ser, en la medida en que se comprende al ente en tanto ente (ser desde comprensión del ser). 3. Ahora bien, la comprensión del ser es una determinación que pertenece esencialmente al Dasein (comprensión del ser desde Dasein), por lo que es pertinente afirmar

55 Heidegger 2006a, p. 389.

56 Von Herrmann 1985, p. 34: «El fenómeno fundamental de la apertura no se determina desde el sí-mismo del hombre, sino que, por el contrario, el sí-mismo se determina desde la apertura». 
que la «esencia del ente humano sólo puede ser captada en su totalidad cuando es interpretada desde la comprensión del ser que es constitutiva a su manera de ser» ${ }^{57}$. Estos tres momentos muestran el movimiento circular del proceder hermenéutico-fenomenológico, pues se arriba al lugar (Dasein), ahora manifestado y aclarado en sus estructuras fenoménicas esenciales, del que inicialmente se puso en marcha (Dasein). Es decir, la interpretación de la comprensión preontológica del ser es circular, porque es radical: surge del vínculo implícito entre ser y Da-sein, y porta en sí ese vínculo; portándolo y sabiéndose procedente de ese vínculo, retorna filosóficamente a él en cuanto lo hace explícito, sacándolo a la luz y desplegándolo teoréticamente.

¿Se reduce, entonces, la investigación heideggeriana a un antropologismo? Esta sospecha se desmonta al atender que al «Dasein» le atañe una ramificación óntico-ontológica, pues fenómeno y término se refieren al ser del hombre ( $D a$ sein) y al mismo tiempo al hombre fáctico (Dasein $)^{58}$. La primera acepción que acentúa el aspecto ontológico (ser del hombre) está validada teoréticamente, porque es el resultado de la mirada fenomenológica sobre el fenómeno «vulgar» óntico (hombre), del que se colige su dimensión constitutivamente ontológica. En su lección de 1928, Heidegger aborda directamente este punto. «Este ente que no sin razón llamamos Da-sein deja ser en la medida en que existe $[. .$.$] en y a través de su ser algo semejante como a un 'ahí'», mentando$ este ahí $(D a)$ en Da-sein no otra cosa que la «apertura del ser» ${ }^{59}$, la cual es abierta y es mantenida abierta en la comprensión del ser. A la luz de ello se hace manifiesto que el estar existiendo en la apertura del ser, al haberla comprendido y al existir comprendiéndola en el desempeño vital cotidiano, ilumina y fundamenta de antemano al Da-sein como tal, al descubrimiento de los entes y al trato intencional con ellos, pues el «ente solamente puede ser experimentado 'de hecho', si el ser ya está comprendido, si bien no asido en conceptos» ${ }^{60}$. En efecto, el ente hombre se cualifica fenoménicamente como Da-sein debido a su entrelazamiento con el ser gracias a la comprensión del ser (cuarto comprobante). Esta duplicidad óntico-ontológica previene de caer en una lectura unilateralmente óntica, lo cual impediría aprehender que la comprensión del ser en tanto factum inicial se plenifica concomitantemente al desarrollo de la analítica del Da-sein.

En este sentido, explicar el Da-sein y la comprensión del ser va de la mano. Como esta comprensión es una determinación fundamental del ente hombre

57 Kalariparambil 1999, p. 11.

58 Ser del hombre: Heidegger 2006a, pp. 25, 55, 133; GA 3, p. 234; GA 22, p. 4; GA 24, p. 237; GA 29/30, p. 258. Hombre: Heidegger 2006a, pp. 7, 46; GA 20, p. 349; GA 21, p. 209; GA 26, p. 171.

59 GA 27, pp. 136, 139.

60 Heidegger 2006a, p. 315. 
(Dasein), Heidegger afirma que la apertura del ser enraíza «ónticamente» en ella ${ }^{61}$, de suerte que el Dasein que existe comprendiendo ser presenta el lugar de aperturación de cualquier posible investigación ontológico-filosófica en absoluto. Esto no significa que lo investigado sea el ente hombre desde cualquiera de las múltiples perspectivas en las que cabe tematizarlo, sino en rigurosa orientación a su comprensión del ser como la puerta adecuada de acceso de la investigación: «la pregunta por el ser no es, entonces, otra cosa que la radicalización de una tendencia ontológica perteneciente esencialmente al Dasein mismo, la comprensión preontológica del ser» ${ }^{62}$. Esta tesis es decisiva, porque expone claramente que la analítica del Dasein va intrínsecamente de la mano con tal comprensión. Veámoslo en tres pasos. Primero, la base de la ontología fundamental como investigación del ser en general, es decir, como una «investigación de los principios» ${ }^{63}$, reposa en el factum de la comprensión preontológica del ser como condición de posibilitación de toda ontología en general, sencillamente porque el ser en general se abre en dicha comprensión. Segundo, esta comprensión pertenece esencialmente al Da-sein, por lo que a éste debe abocarse la analítica existencial. Por ende, tercero, el desarrollo de la analítica es simultáneamente el despliegue implícito de la comprensión preontológica del ser, a saber, como la instancia que le aporta su dirección estrictamente «ontológica» (quinto comprobante).

\section{CONCLUSIÓN}

Con un propósito a sabiendas restringido en base al alcancemultidireccional de este fenómeno abordamos la comprensión preontológica del ser partiendo de su carácter como factum fundamental en su vaguedad promedio inicial, de lo que se desprende lo siguiente. Existiendo a priori en el suceso de su propia trascendencia el Dasein está arrojadamente referido y se refiere proyectivamente al ser en general, siempre ya abierto concretamente como las diversas maneras de ser desplegadas en todo ente compareciente comprendido y con el cual, consecuentemente, es posible el comportamiento estructurado intencionalmente. Esta comprensión del ser en general, que pertenece a un ser-con-en-el-mundo, se concreta fácticamente en la comprensión del Dasein respecto a su propio ser, al ser de sus prójimos y al ser de los entes que carecen de su carácter ontológico, por lo que una analítica del Dasein no solo presupone la comprensión del ser como factum, sino que simultáneamente la

$61 C f$. Heidegger 2006a, pp. 13, 212, 436.

62 Heidegger 2006a, p. 15.

63 Heidegger 2006a, p. 7. La orientación al campo temático último, fundamental y originario propio de la filosofía determina la investigación heideggeriana ya desde su primera lección, cf. GA 56/57, p. 24. 
va atestiguando a medida que el Dasein mismo es expuesto en sus estructuras y momentos esenciales. Mostrándose temáticamente de soslayo a la luz de aquellos fenómenos, lo que se ha resaltado en cinco comprobantes, se logra hacer visible fenomenológico-interpretativamente su plena acreditación indirecta.

\section{REFERENCIAS BIBLIOGRÁFICAS}

ESCUDERO, A. J. 2010: Heidegger y la genealogía de la pregunta por el ser. Una articulación temática y metodológica de su obra temprana. Barcelona: Herder.

CROWELL, S. 2013: Normativity and Phenomenology in Husserl and Heidegger. New York: Cambridge University Press.

DAVOLI, G. 2013: Heidegger und die Frage nach dem Sinn von Sein: das Dasein und das Nichts, Berlin: LIT.

DREYFUS, H.L. 1991: Being-in-the-World. A Commentary on Heidegger's Being and Time, Division I. Massachusetts: MIT Press.

DREYFUS, H.L. 2017: Background Practices. Essays on the Understanding of Being, Wrathall, M. A. (ed.). Oxford: Oxford University Press.

ESCUDERO PÉREZ, A. 2010: «Heidegger y la pregunta por el sentido del ser». Endoxa. Series Filosóficas, núm. 26, pp. 187-221.

GARCÍA NORRO, J.J. 2015: «El cuidado como el ser del Dasein (§§39-44)», en Rodríguez, R. (coord.): Ser y Tiempo de Martin Heidegger. Un comentario fenomenológico. Madrid: Tecnos, pp. 167-195.

GETHMANN, C.F. 1987: «Philosophie als Vollzug und als Begriff. Heideggers Identitätsphilosophie des Lebens in der Vorlesung vom Wintersemester 1921/22 und ihr Verhältnis zu Sein und Zeit», en Dilthey-Jahrbuch, 4/1986-87, pp. 27-53.

HABERMAS, J. 1983: Der philosophische Diskurs der Moderne. Zwölf Vorlesungen. Frankfurt a.M.: Suhrkamp.

HEIDEGGER, M. 1976: Logik. Die Frage nach der Wahrheit (Gesamtausgabe 21). Frankfurt a.M.: Klostermann.

HEIDEGGER, M. 1978: Metaphysische Anfangsgründe der Logik im Ausgang von Leibniz (Gesamtausgabe 26). Frankfurt a.M.: Klostermann.

HEIDEGGER, M. 1979: Prolegomena zur Geschichte des Zeitbegriffs (Gesamtausgabe 20). Frankfurt a.M.: Klostermann.

HEIDEGGER, M. 1982: Vom Wesen der menschlichen Freiheit. Einleitung in die Philosophie (Gesamtausgabe 31). Frankfurt a.M.: Klostermann.

HEIDEGGER, M. 1991: Kant und das Problem der Metaphysik (Gesamtausgabe 3). Frankfurt a.M.: Klostermann.

HEIDEGGER, M. 1994: Einführung in die phänomenologische Forschung (Gesamtausgabe 17). Frankfurt a.M.: Klostermann.

HEIDEGGER, M. 1995: Phänomenologische Interpretation von Kants Kritik der reinen Vernunft (Gesamtausgabe 25). Frankfurt a.M.: Klostermann. 
HEIDEGGER, M. 1997: Der deutsche Idealismus (Fichte, Schelling, Hegel) und die philosophische Problemlage der Gegenwart (Gesamtausgabe 28). Frankfurt a.M.: Klostermann.

HEIDEGGER, M. 1999: Zur Bestimmung der Philosophie (Gesamtausgabe 56/57). Frankfurt a.M.: Klostermann.

HEIDEGGER, M. 1993: Grundprobleme der Phänomenologie (1919/20) (Gesamtausgabe 58). Frankfurt a.M.: Klostermann.

HEIDEGGER, M. 2001: Einleitung in die Philosophie (Gesamtausgabe 27). Frankfurt a.M.: Klostermann.

HEIDEGGER, M. 2004a:Die Grundbegriffe der antiken Philosophie(Gesamtausgabe 22), Frankfurt a.M.: Klostermann.

HEIDEGGER, M. 2004b: Die Grundbegriffe der Metaphysik. Welt - EndlichkeitEinsamkeit (Gesamtausgabe 29/30). Frankfurt a.M.: Klostermann.

HEIDEGGER, M. 2005a: Die Grundprobleme der Phänomenologie (Gesamtausgabe 24). Frankfurt a.M.: Klostermann.

HEIDEGGER, M. 2005b: Phänomenologische Interpretationen ausgewählter Abhandlungen des Aristoteles zur Ontologie und Logik (Gesamtausgabe 62). Frankfurt a.M.: Klostermann.

HEIDEGGER, M. 2006a: Sein und Zeit (19 ed). Tübingen: Niemeyer.

HEIDEGGER, M. 2006b: Geschichte der Philosophie von Thomas von Aquin bis Kant (Gesamtausgabe 23). Frankfurt a.M.: Klostermann.

HEIDEGGER, M. 2016: Vorträge. Teil 1: 1915-1932 (Gesamtausgabe 80.1). Frankfurt a.M.: Klostermann.

HEIDEGGER, M. 2018: Zu eigenen Veröffentlichungen (Gesamtausgabe 82). Frankfurt a.M.: Klostermann.

HERNÁNDEZ-PACHECO, J. 1983: Die Auflösung des Seins. Die Entwicklung einer phänomenologischen Ontologie im Denken Martin Heideggers. Wien: VWGÖ.

KALARIPARAMBIL, T. S. 1999: Das befindliche Verstehen und die Seinsfrage. Berlin: Duncker \& Humblot.

LAFONT, C. 1994: Sprache und Welterschließung. Zur linguistischen Wende der Hermeneutik Heideggers. Frankfurt a.M.: Suhrkamp.

MEIKE, S. 2010: Abkehr vom Subjekt. Zum Sprachdenken bei Heidegger und Buber. Freiburg/München: Alber.

OBERDIECK, J. 2009: Sorge und Begehren. Zur Konzeption der Seinsfrage in Sein und Zeit. Berlin: Parodos.

OKRENT, M. 1988: Heidegger's Pragmatism. Understanding, Being, and the Critique of Metaphysics. Ithaca: Cornell University Press.

RODRÍGUEZ, R. 2006: Heidegger y la crisis de la época moderna. Madrid: Síntesis.

ROSALES, A. 2018: «Consideraciones sobre el giro», en Rodríguez, R. (ed.): Guía Comares de Heidegger. Granada: Comares, pp. 99-117.

RUBIO, R.G. 2015: «El estar-en-el-mundo en general como constitución fundamental del Dasein (§§12-13)», en Rodríguez, R. (coord.): Ser y Tiempo de Martin Heidegger. Un comentario fenomenológico. Madrid: Tecnos, pp. 71-87.

TIETZ, U. 2005: Heidegger. Leipzig: Reclam. 
TÖMMEL, T.N. 2013: «Wie bereit ich's, daß Du wohnst im Wesen?. Heidegger über Liebe und die Eigentlichkeit des Anderen in den Marburger Jahren», en: T. Keiling (ed.), Heideggers Marburger Zeit. Themen, Argumente, Konstellationen. Frankfurt a.M.: Klostermann, pp. 335-349.

TUGENDHAT, E. 1979: Selbstbewußtsein und Selbstbestimmung. Sprachanalytische Interpretationen. Frankfurt a.M.: Suhrkamp.

VAN REIJEN, W. 2009: Martin Heidegger. Paderborn: Wilhelm Fink.

VOLPI, F. 2012: Heidegger y Aristóteles. Buenos Aires: FCE.

VON HERRMANN, F.-W. 1985: Subjekt und Dasein. Interpretationen zu «Sein und Zeit». Frankfurt a.M.: Klostermann.

VON HERRMANN, F.-W. 1987: Hermeneutische Phänomenologie des Daseins. Eine Erläuterung von «Sein und Zeit», Band I. Frankfurt a.M.: Klostermann.

VON HERRMANN, F.-W. 1991:Heideggers «Grundprobleme der Phänomenologie». Zur «Zweiten Hälfte»von «Sein und Zeit». Frankfurt a.M.: Klostermann.

VON HERRMANN, F.-W. 2000: Hermeneutik und Reflexion. Der Begriff der Phänomenologie bei Heidegger und Husserl. Frankfurt a.M.: Klostermann.

VON HERRMANN, F.-W. 2005: Hermeneutische Phänomenologie des Daseins. Ein Kommentar zu «Sein und Zeit», Band II. Frankfurt a.M.: Klostermann.

VON HERRMANN, F.-W. 2019: Transzendenz und Ereignis. Heideggers «Beiträge zur Philosophie (Vom Ereignis)». Ein Kommentar. Würzburg: K\&N.

Christian Ivanoff Saboga es Doctor por la Universidad de Heidelberg.

Lineas de investigación

Ontología, metafísica y fenomenología hermenéutica

Publicaciones recientes

IVANOFF-SABOGAL y ARIS TSOULLOS 2021: «Der zeitliche Sinn der ontologischen Rückstrahlung», Heidegger Studien 37 (2021).

2021: Mitdasein und Seinsfrage. Systematische Untersuchung der Interexistenzialität in Heideggers Fundamentalontologie, Berlin: Duncker \& Humblot.

Correo electrónico: christian8ivanoff@gmail.com 